\title{
Compliance with gluten free diet in coeliac disease
}

\author{
J COLACO, B EGAN-MITCHELL, F M STEVENS, P F FOTTRELL, C F MCCARTHY, \\ AND B MCNICHOLL
}

Departments of Paediatrics and Medicine, Regional Hospital and University College and the Department of Biochemistry, University College, Galway, Ireland

SUMmARY Fifty two children in whom coeliac disease was confirmed by persistent enteropathy while they were taking gluten were monitored to assess the effects of compliance with a gluten free diet (GFD). Between the ages of 17.8 and 18.5 years height (in 45 patients followed up for a mean of 14.9 years) and weight (in 43 followed up for a mean of 15.2 years) were significantly lower in those complying poorly with a GFD compared with those complying well. Of the 37 patients still attending the clinic after a mean of 25 years, having been followed up for a mean of 18.4 years, 16 who had complied well with the diet had normal or only slightly abnormal mucosal morphology whereas all 10 who had not complied had abnormal morphology. In these 10 lactase, sucrase, and alkaline phosphatase activities were significantly less than values in those who complied well. Mucosal sucrase and alkaline phosphatase activities in those who complied well were no different from those in a control population, whereas lactase activity was significantly lower. It is concluded that failure to comply with a GFD during childhood results in decreased adult stature and in persisting active enteropathy with depressed brush border enzyme activity.

Sheldon reviewed 57 young adults who had been diagnosed as having coeliac disease in childhood and found that six were stunted ${ }^{1}$; there had, however, been a delay of at least seven years before diagnosis. Of the 57, 13 had had a clinical relapse, and 19 had low serum folate and 11 low serum iron concentrations. The initial diagnosis had been made without intestinal biopsy. Young and Pringle from a series of 110 children regarded as having coeliac disease, followed up 44 for between eight and 19 years $^{2} ; 11$ out of 20 receiving a strict gluten free diet (GFD), six out of 16 receiving a partial GFD, and only one out of eight receiving a normal diet were above the 50th height centile, and five receiving a normal diet were below the 3 rd centile. No initial biopsy was done in 13 of the 110 , and in the 44 followed up for some years repeat biopsies were not done, progress being assessed by anthropometric and clinical criteria.

We followed up a group of 52 children for a mean of 18.4 years to see if there was an association between their growth, general health, mucosal morphology, and enzymology and their compliance with a GFD. We believe that this is the first study in which the initial diagnosis was confirmed in all cases by the finding of persisting gluten enteropathy and in which serial biopsies were performed.

\section{Patients and methods}

We studied 52 children, 47 of whom had taken part in a previous study $;^{3}$ the mean age at diagnosis was 3.3 years (range 6 months to 12 years). The children comprised 32 girls and 20 boys; because there was no difference between the sexes in either compliance with diet or outcome the results were combined. In 42 children persisting gluten intolerance was confirmed by mucosal relapse on return to a normal diet; 10 , whose dietary compliance was poor, were regarded as having persisting gluten intolerance because active mucosal enteropathy was found after a mean of five years' treatment. Intestinal biopsy samples were taken with Crosby or Watson capsules, morphological appearances being graded 0 to $\mathrm{III}^{4}(0=$ normal and $\mathrm{I}=$ slight, II = moderate, and III = severe villous aplasia); grades II and III were regarded as diagnostic of active coeliac disease. Mucosal enzymes were assayed as previously described. ${ }^{5}$ Throughout the study the appearances on dissecting microscopy and histological examination were graded by $\mathrm{BMcN}$. Specimens were assessed in batches, by dissecting microscopy some days after the biopsy and histologically some weeks later, usually without any 
clinical information being available. Clinical details may have been known in some instances, particularly early in the study when techniques were being developed and occasionally when there were pressing demands for a report from parents or colleagues, as we were providing a service for other patients as well as our own. Haemoglobin, serum, red cell folate, and serum iron concentrations were measured by accepted methods, some of which changed during the study. The mean number of biopsy specimens obtained in the 37 patients who attended throughout was $5 \cdot 18$. Height was measured during the last 15 years of the study with a Harpenden stadiometer and, before that by nursing staff with a less accurate stadiometer mounted on the wall; their technique was evaluated periodically. Height and weight were plotted on the same kind of charts throughout. ${ }^{6}$

Dietary compliance was assessed by $\mathrm{BMcN}$ or BEM, who were in clinical charge of the patients until at least their 18th year, when most were transferred to the care of $\mathrm{CMcC}$. Parents and children were questioned carefully at each attendance about their diet, but detailed analysis was not attempted. We believe that in the case of preschool children compliance is usually good and it is easy for the parent to oversee the diet. With school children, however, the child's word has to be taken on trust concerning food eaten outside the house. We believe that on most occasions when a child is asked 'How often do you eat what you are not supposed to?' he gives a reasonably honest response and that our assessments of compliance were generally valid. Compliance was considered good if wheat or rye were rarely or never eaten (good GFD), moderate if the child admitted to occasional or regular indulgence in small amounts (moderate GFD), and poor if we considered that consumption of wheat products was regular and considerable or that the diet was virtually normal (poor GFD). Regular home visits by a dietitian or other health worker might have improved the accuracy of our categorisations, but we did not attempt this. Particularly in children

Table 1 Height and weight centiles and dietary compliance in patients aged between 17.8 and 18.5 years

\begin{tabular}{|c|c|c|c|}
\hline & $\begin{array}{l}\text { Good (FFD } \\
(n=27)\end{array}$ & $\begin{array}{l}\text { Moderate (iFD) } \\
(n=8)\end{array}$ & $\begin{array}{l}\text { Poor (iFI) } \\
(n=I(0)\end{array}$ \\
\hline Mcan height centile & $53 \cdot 8$ & $31 \cdot 2$ & 26.6 \\
\hline SEM & $6 \cdot 3$ & $11 \cdot 11$ & $8 \cdot 6$ \\
\hline SD & $\begin{array}{l}32 \cdot 1 \\
(n=27)\end{array}$ & $\begin{array}{l}31 \cdot 1 \\
(n=7)\end{array}$ & $\begin{array}{l}27 \cdot 2 \\
(n=9)\end{array}$ \\
\hline Mean weight centile & 60.3 & $4 x \cdot 5$ & $32 \cdot 5 \%$ \\
\hline SEM & $5 \cdot 8$ & $9 \cdot 5$ & $11 \cdot 1)$ \\
\hline $\mathrm{SD}$ & $30 \cdot 3$ & $25 \cdot 2$ & $29 \cdot()$ \\
\hline
\end{tabular}

Poor $v$ good (iFI): $p<0 .(12) ; p<0 .(15$. with a poor GFD there was little if any doubt because non-compliance was readily admitted and continued despite regular exhortations from both us and the family doctors.

At the time of diagnosis there were no significant differences in age at diagnosis, birth weight, weight, or height between those who subsequently differed in their dietary compliance. Until the last five years of the study oatmeal was allowed in the diet, but subsequently it was discouraged.

Student's $t$ test was used to analyse data; analysis was then repeated with the Wilcoxon rank sum test, and no differences between the results obtained with the two tests were found.

\section{Results}

Height, measured between the ages of 17.8 and 18.5 years, was taken to represent final height and was recorded for 45 patients, who had been followed up for a mean of 14.9 years (range 8.25 to 17.5 ). Weight was available for 44 , the mean period of follow up being $15 \cdot 2$ years (range 8.25 to $17 \cdot 5$ ) (Table 1 ). Mean height and weight were significantly lower in those with a poor GFD compared with those with a good GFD; measurements in those with a moderate GFD were intermediate and not significantly different. Those who complied poorly with the diet began to do so between one and four years after diagnosis. At the end of the period of review 37 patients were still attending the clinic; their mean age was 25 and they had been under observation for a mean of 18.4 years (range $8 \cdot 25$ to $28 \cdot 5$ ). Of the 37,16 with a good GFD had normal or slightly abnormal mucosa (10 grade 0 and six grade I), but all 10 with a poor GFD had abnormal mucosa (three grade II and seven grade III); the 11 with a moderate GFD showed intermediate changes (seven grade I and four grade II). Lactase, sucrase, and alkaline

Table 2 Mean lactase, sucrose, and alkaline phosphatase activity in 37 patients (mean age 25)

\begin{tabular}{|c|c|c|c|c|}
\hline & $\begin{array}{l}\text { Control } \\
\text { group } \\
(n=I l())\end{array}$ & $\begin{array}{l}\text { Good } \\
\text { GFD } \\
(n=I 6)\end{array}$ & $\begin{array}{l}\text { Moderate } \\
G F D \\
(n=I I)\end{array}$ & $\begin{array}{l}\text { Poor } \\
\text { (FFI) } \\
(n=I 0)\end{array}$ \\
\hline Lactase (IU/g) & 4()$\cdot 2$ & $26 \cdot 1+$ & $17 \cdot 6$ & $4.6 \%$ \\
\hline SD & $20 \cdot 9$ & $12 \cdot 1$ & $15 \cdot 9$ & $2 \cdot 7$ \\
\hline SEM & $2 \cdot 1)$ & $3 \cdot()$ & $4 \cdot 8$ & 0.9 \\
\hline Sucrase (IU/g) & $6(1) \cdot 3$ & $53 \cdot 0$ & $44 \cdot()$ & $17 \cdot 6 \%$ \\
\hline SD & $26 \cdot 2$ & $18 \cdot 8$ & $26 \cdot 8$ & $10 \cdot 2$ \\
\hline SEM & $2 \cdot 5$ & 4.7 & 8.5 & $3 \cdot 1$ \\
\hline \multicolumn{5}{|c|}{ Alkaline phosphatase } \\
\hline (IU/mg) & $18 \cdot 2$ & $17 \cdot 7$ & $15 \cdot 5$ & $5.5 \%$ \\
\hline SD & $5 \cdot 6$ & $5 \cdot 2$ & $9 \cdot 5$ & 2.9 \\
\hline SEM & 0.5 & 1.3 & $3 \cdot 0$ & 0.9 \\
\hline
\end{tabular}

†Poor $v$ good GFD: $\mathrm{p}<() \cdot(k) 1:$ good GFD $v$ controls: $\mathrm{p}<(1 \cdot()) 1$

"Controls were matched for age." 
phosphatase activities were all significantly lower in the 10 with a poor GFD compared with the 16 with a good GFD, those with a moderate GFD again occupying an intermediate position (Table 2). Sucrase and alkaline phosphatase activities in those having a good GFD were not significantly different from those in controls, but lactase activity remained significantly less. In these 37 patients there were no significant differences in haemoglobin, serum iron, or red cell folate concentrations between the three dietary groups.

\section{Discussion}

Failure to adhere to a GFD retards growth and results in decreased adult stature. It also results in persisting active enteropathy in the upper intestine with decreased activity of those brush border enzymes that were assayed. We believe that patients with such active enteropathy will sooner or later suffer from further effects of chronic malabsorption, particularly mineral and vitamin deficiencies, and there may be possible adverse effects on fertility in women.

It is disappointing that compliance in adhering to a GFD was poor in so many cases and that as many as 15 out of 52 patients eventually stopped attending the clinic. In this part of the country coeliac disease has been given a lot of publicity in the media and there is an active branch of the Irish Coeliac Society, so we presume that dietary non-compliance is due to the natural rebellion of teenagers and young adults against a restriction on their behaviour whose basis they will not accept. The most important question in the long term is whether adherence to a GFD will reduce or minimise the risk of early death and gut malignancy, or both. Among 547 patients with coeliac disease attending this centre 44 have died at a mean age of 56.3 years, 23 of them from malignant disease of the gut at a mean age of 57.5 years. There is no evidence so far about whether a GFD reduces these risks, but it has been our policy to inform children who are reaching a responsible age about them. Even though we cannot definitely assure them that keeping to a GFD will ensure a normal life span, we can be certain about the adverse effects of non-compliance on growth and almost certain about effects on future health.

The failure of lactase activity to return to normal in patients receiving a good GFD is something we have previously reported ${ }^{7}$ and has also been found by other groups. Possibly lactase is more readily suppressed by gliadin than sucrase and alkaline phosphatase, and its failure to return to normal activity may be due to small amounts of gliadin in a 'good' GFD. One study proposed that a strict GFD did lead to normal lactase activity because the measurements, though lower than in controls, were not significantly so. ${ }^{8}$ There is also some evidence that lactase activity in first degree relatives of patients with coeliac disease is lower than that in a control population. ${ }^{9}$

Since the paper was submitted, four of the 15 who had stopped attending returned for review. All said that they were keeping to strict gluten free diets. At a mean age of 27.5 years, having been followed up for a mean of 22.7 years, their mean height centile was 74 . Biopsies have not yet been done.

We thank our colleagues in hospitals and laboratories who helped us, and the Medical Research Council of Ireland, and Wcllcomc Trust, and the Western Health Board for financial help.

\section{References}

1 Sheldon W. Prognosis in carly adult life of cocliac children treated with a gluten-free diet. Br Med J 1969;i:401-4.

2 Young WF, Pringle EM. 110 children with cocliac disease. Arch Dis Child 1971:46:421-37.

${ }^{3}$ McNicholl B, Egan-Mitchell B, Fottrell PF. Variability of gluten intolerance in treated childhood coeliac disease. Gut 1979;20:126-32.

4 McNicholl B, Egan B. Jejunal biopsy in celiac disease. Clin Pediatr 1968;7:544-52.

${ }^{5}$ Keane R, O'Grady JG, Sheil J, et al. Intestinal lactase, sucrase and alkaline phosphatase in relation to age, sex and site of intestinal bopsy in 477 Irish subjects. J Clin Pathol 1983;36:74-7.

6 Tanner JM, Whitchouse RH. Standards for height and weight of British children from birth to maturity. Lancet 1959;ii:1088.

${ }^{7}$ McNicholl B, Egan-Mitchell B, Stevens FM, et al. Mucosal recovery in treated childhood celiac disease (gluten-sensitive enteropathy). J Pediatr 1976;89:418-24.

${ }^{\star}$ Dissanayake AS, Truelove SC, Whitehead R. Jejunal mucosal recovery in coeliac disease in relation to the degree of adherence to a gluten-free diet. $Q J$ Med 1974;53:161-85.

${ }^{9}$ O'Grady JG, Cryan EM. Stevens FM, et al. Splenic function and intestinal enzyme activity in cocliac relatives; is there a coeliac trait? Gut 1982;23:919-20.

Correspondence to Professor B McNicholl, Department of Paediatrics, Regional Hospital, Galway, Ireland.

Received 24 February 1987 